\title{
A DIFERENCIAÇÃO FUNCIONAL DA RELIGIÃO NA TEORIA SOCIAL DE NIKLAS LUHMANN*
}

\section{João Paulo Bachur}

\section{Religião como sistema?}

O objeto deste artigo é investigar o lugar da religião na teoria de sistemas sociais de Niklas Luhmann com a finalidade de destacar algumas das ambiguidades e contradições que a teoria enfrenta ao lidar com o fenômeno religioso. Nossa hipótese de pesquisa pode ser sintetizada da seguinte maneira: mesmo partindo das premissas internas à teoria, a religiāo não deve ser considerada um sistema social autopoiético tal como os demais. Isso não quer dizer,

* O presente artigo é uma versão revista da seção "A função da religião" de minha tese de doutorado Distanciamento e crítica: limites e possibilidades da teoria de sistemas de Niklas Luhmann, FFLCH/USP, 2009. Agradeço a leitura criteriosa e os valiosos comentários dos pareceristas anônimos que avaliaram este texto.

Artigo recebido em fevereiro/2010

Aprovado em fevereiro/2011 de maneira alguma, que a religião tenha perdido relevância na sociedade funcionalmente diferenciada. Por óbvio, nosso propósito não é fazer uma crítica abstrata da religião nem questionar sua importância na sociedade contemporânea. Rigorosamente, não se trata de um estudo de sociologia da religião propriamente dito, mas de uma abordagem crítica à teoria de sistemas sociais pelo ângulo da diferenciação funcional da religião. Ou seja, investigaremos não a religião em sua diversidade de manifestações empíricas, mas apenas os instrumentos analíticos de que dispõe a teoria de sistemas para a observação do fenômeno religioso.

Uma das poucas iniciativas teóricas recentes que assume a tarefa de construir uma teoria geral da sociedade, a obra de Luhmann apresenta-se como teoria de sistemas sociais funcionalmente diferenciados (sistemas autopoiéticos). Luhmann é conhecido por uma produção bibliográfica extensa, considerada por muitos de difícil acesso, tanto 
por conta das definições tautológicas e paradoxais como em razão da absorção de influências teóricas e epistemológicas bastante heterodoxas, tais como a teoria geral de sistemas, a cibernética, o construtivismo e o cálculo das formas. Não temos condiçôes de proceder aqui a uma apresentação introdutória da teoria social luhmanniana $;^{1}$ suas categorias conceituais centrais ficarão progressivamente mais nítidas com o transcurso de nossa argumentação.

O enquadramento da religião é certamente um ponto polêmico para a teoria de sistemas sociais. ${ }^{2}$ O problema é que o debate dessa questão na literatura especializada não é levado às últimas consequências: não basta reconhecer as ambiguidades ou insuficiências de Luhmann na observação do fenômeno religioso; é preciso ir além e investigar se algum reparo conceitual não se faz necessário diante da dificuldade da teoria de sistemas em face da religião.

A religião, como toda operação social - isto é, como toda operação genuinamente social: conduzida não pela consciência depurada da moldura comunicativa provida por sistemas funcionais, mas pela interpenetração entre a produção de sentido nos sistemas sociais e a produção de sentido pelas consciências empíricas - deve ser entendida como comunicação (Luhmann, 2000b, p. 13). A sociedade não é composta de pessoas; a esfera social [Sozialität] não é derivada da racionalidade subjetiva: comunicação e consciência constituem âmbitos simbólicos autônomos que funcionam com lógicas próprias. É claro, não existe comunicação sem o envolvimento das consciências empíricas, da mesma forma como a consciência não existe in abstractu, destacada da sociedade. O sentido é a forma que permite o acoplamento estrutural entre elas, de modo que comunicação e consciência constituem esferas autorreferentes independentes entre si, mas que apenas podem existir imbricadas uma na outra.

Neste ponto reside a alegada mudança de paradigma em relação não apenas à teoria social, mas também em relação à teoria geral de sistemas: ao lado das máquinas e dos organismos vivos, tradicionalmente conceituados como sistemas fechados, Luhmann identifica sistemas psíquicos e sociais como sendo operativamente fechados, mas cognitivamente abertos. Com isso, Luhmann distin- gue duas esferas independentes de autorreferência - consciência, de um lado, e sistemas sociais, de outro, compreendidas, neste último âmbito, interações, organizações e sociedade (Luhmann, 1984, pp. 16-22). A categoria da autopoiese expressa assim diferentes modalidades de autorreferência operativa.

Sistemas sociais definem-se pela diferença sistema/ambiente: são âmbitos comunicativos socialmente estruturados e operativamente fechados que se reproduzem conforme lógicas próprias e (relativamente) autônomas entre si - isso é o que se conhece por autopoiese e está relacionado com o desempenho, por um sistema, de uma função considerada relevante para a sociedade como um todo [Gesamtgesellschaft] (Idem, pp. 30-31). Neste contexto, vale indagar: a religião pode ser considerada um sistema autopoiético tal como os demais (política, economia, direito, ciência etc.)? O fechamento operacional da religião é equivalente ao da economia monetária ou ao do sistema jurídico? A comunicação religiosa é capaz de estruturar sua própria complexidade de forma a manter sua reprodução autopoiética em medida equivalente à dos demais sistemas funcionais?

Vale considerar que Luhmann não pressupõe um desenvolvimento homogêneo entre todos os sistemas autopoiéticos, pois eles podem apresentar diferentes graus de diferenciação interna, de acordo, por exemplo, com seus acoplamentos estruturais ou seus respectivos meios de comunicação simbolicamente generalizados: "A diferenciação funcional não garante de modo algum chances igualmente boas para todos os sistemas funcionais, para a economia tanto quanto para a religião, para o direito tanto quanto para a arte" (Luhmann, 1997, p. 770).

No entanto, mesmo à luz dessa constatação, Luhmann afirma em diversos momentos que a religião deve ser considerada um sistema autopoiético como os demais:

[...] a religião se encontra hoje em uma sociedade cujas estruturas foram substituídas pela diferenciação funcional. Daí não decorre problema algum no fato de que também a religião encontra seu lugar como um sistema funcional entre os outros [...] (2000b, p. 209). 
[...] a diferenciação funcional [Ausdifferenzierung] do sistema religioso conduz ao fechamento operacional e à reprodução autopoiética desse sistema [...] (Idem, p. 223).

Isso nos obriga a reconhecer que há, na moderna sociedade mundial, um sistema funcional para a religião que opera em bases mundiais e que se determina como religião, diferenciando-se dos demais sistemas funcionais (Idem, p. 272).

Vale, desde já, avançar o cerne de nossa argumentaçăo. À primeira vista, e diferentemente dos demais sistemas, a especificidade da religião estaria no fato de que a participação na comunicação religiosa parece depender muito estreitamente do comprometimento e do engajamento efetivo da consciência - por intermédio da $f e ́$-, o que dificultaria a manutenção de sua fronteira sistema/ambiente. Este é o argumento central que pretendemos demonstrar ao longo deste artigo.

Embora a compreensão do alcance da teoria social de Luhmann exija lidar com sua arquitetura labiríntica, é preciso conceder que muitos círculos luhmannianos sobrevivem da mera reprodução estilística de suas fórmulas conceituais. A fim de contornar este risco, procuraremos ilustrar historicamente nossa argumentação com recurso à sociologia da religião de Max Weber - sem, no entanto, incluí-la em nosso escopo de pesquisa. Vale desde já a ressalva: nosso recurso a Weber é meramente exemplificativo; trata-se apenas de ilustrar os argumentos conceituais apresentados para a observação da diferenciação funcional da religião em Luhmann. Aliás, não se trata sequer da comparação entre as categorias empregadas pelos dois autores, tendo em vista a disparidade de seus respectivos pontos de partida: ação como interpretação de um comportamento a partir do sentido subjetivamente visado pelo agente (Weber, 1980, p. 1); comunicação como emergência produzida no transcurso das operaçōes autopoiéticas de sistemas funcionalmente diferenciados (Luhmann, 1987b).

Para demonstrar nossa hipótese, apresentaremos a religião como um caso específico de diferenciação funcional que ocorre por reação à diferencia- ção concomitante de múltiplos sistemas funcionais da sociedade (seção 2); e que, por essa razão, significa a privatização da experiência religiosa (seção 3). Ao final, sugeriremos um breve reparo capaz de adaptar o aparato conceitual da teoria de sistemas sociais à observação do fenômeno religioso na sociedade contemporânea (seção 4).

\section{A diferenciação funcional "por reação" da religiáo}

À primeira vista, pode causar espécie o argumento de que a religião passara por um processo de diferenciação funcional "por reação". Afinal, a originalidade que Luhmann reivindica para sua teoria da comunicação está no fato de concebê-la como operação prática, concretamente executada por sistemas sociais (e não por sujeitos, no sentido em que esta categoria é empregada pela tradição da teoria social). Ou seja, trata-se de conceber a comunicação não como a transferência [Übertragung] de uma mensagem, como se fosse uma coisa, de uma consciência a outra (Luhmann, 1986, p. 168); mas como realidade emergente, "autocatalisada", por assim dizer, a partir de uma situação de dupla contingência - definida, portanto, justamente por sua própria improbabilidade. $\mathrm{Na}$ situação em que a contingência é radicalizada reciprocamente para os dois lados de uma diferença (Idem, 1984, pp. 153ss.), torna-se improvável que alguma operação comunicativa se estabeleça (Idem, 1981). Mas é justamente a partir desta improbabilidade que a comunicação se estrutura: um dos polos introduz uma diferença que permite erguer uma fronteira sistema/ambiente e, com isso, condicionar a comunicação. A ruptura da dupla contingência é chamada assimetrização e, por essa razão, Luhmann afirma que "[o] sistema assimetriza-se - a si mesmo!" (Idem, 1984, p. 65). Logo, nenhum sistema autopoiético poderia se diferenciar literalmente por reação - ao contrário, apenas por autocatálise.

Mas a religião se diferencia de fato por reação:

Pode-se atribuir à economia, à política, à ciência e, desde o século XVIII, também à educação o papel de âmbitos funcionais impulsionado- 
res [da diferenciação funcional da sociedade]; à família e à religião ao contrário o papel de possibilitadores. [...] A passagem a uma sociedade funcionalmente diferenciada é impulsionada então por outros âmbitos funcionais. Por isso, a crescente diferenciação também do sistema da religião redunda como efeito colateral [Nebeneffekt]. As consequências atingem o sistema religioso de maneira negativa, e isso desde meados do século XVI, ou seja, antes que o sistema religioso precise reagir à secularização. [...] Reagir simultaneamente: (i) à não-identidade, crescentemente identificável, entre o sistema da sociedade e o sistema religioso; (ii) à diferenciação funcional da políti$\mathrm{ca}$, da ciência e da economia internamente à sociedade; (iii) à segmentação interna do sistema religioso; e, por fim, de maneira correlata a tudo isso, (iv) à crescente diferenciação entre o sistema da sociedade em face das pessoas individuais (Idem, 1977, pp. 256-257, grifos no original).

Esta afirmação é menos uma contradição interna à teoria do que o ponto de partida para demonstrarmos nosso argumento. A religiāo representa um caso peculiar de diferenciação funcional por uma razão quase simples: partindo da hegemonia por ela exercida sobre todos os aspectos da vida na Idade Média, os sistemas sociais diferenciaram-se da sociedade na medida em que se diferenciaram concomitantemente da religião. A passagem à sociedade funcionalmente diferenciada tem então um duplo significado: enquanto os sistemas funcionais se diferenciaram da sociedade e, nessa medida, diferenciaram-se simultaneamente da religião; a própria religião, por sua vez, diferenciou-se funcionalmente neste movimento de conjunto. Trata-se de reconhecer a especificidade histórica da diferenciação funcional da religião que ocorre, na verdade, como efeito colateral, em reação à diferenciação funcional dos âmbitos não religiosos da sociedade.

Originalmente, a segurança da religião estava na sociedade mesma; religião e sociedade não se permitiam distinguir (Idem, 1989a, p. 259). A partir da disjunção entre elas, tem-se uma via para a crescente fragmentação da ordem moral-cosmológica feudal - "e nós cogitamos que estas transformações não tenham sido desencadeadas por meio de uma dinâmica própria na história das ideias internamente ao sistema religioso, mas por meio de uma crescente diferenciação de outros sistemas funcionais" (Idem, p. 276). A sequência de nosso argumento exige então considerar a desagregação da ordem cosmológica e moral-religiosa da sociedade feudal.

Ilustraremos a bifurcação da sociedade em um lado religioso e um lado não religioso com recurso ao clássico texto da Consideração intermediária: teoria dos niveis e direçôes da rejeição religiosa do mun$d o$, fecho do primeiro tomo dos escritos de sociologia da religião de Weber, a fim de demonstrar por que a diferenciação funcional da religião pode ser considerada um processo reativo.

De maneira muito geral, a religião se caracteriza pelo código binário transcendência/imanência: o sentido da imanência (a existência mundana) é remetido à transcendência; a comunicação religiosa atribui sentido à atuação mundana ao reportá-la à transcendência, à vida para além deste mundo (Idem, 1977, 1989a e 2000b). A referência a Weber já ajuda a concretizar o significado histórico do código transcendência/imanência:

A necessidade de salvação, cultivada conscientemente como conteúdo da religiosidade, originou-se sempre e em toda parte - apenas gravada com força diferente quanto à clareza dessa relação - como consequência da busca por uma racionalização sistemática e prática da realidade da vida. Expresso de outra maneira: pela reivindicação - que se tornou nesse nível um pressuposto específico de toda religião - de que o curso do mundo, pelo menos até onde ele pode afetar os interesses das pessoas, seja um processo de alguma maneira dotado de significado. Essa reivindicação apareceu, como vimos, de maneira natural e antes de tudo como o problema geral do sofrimento injustificado, ou seja, como o postulado de uma compensação justa para a distribuição desigual das fortunas individuais intramundanas (Weber, 1988b, p. 567). 
Nas associações humanas mais remotas, a religião desenvolveu-se com a função de transformar o indeterminado em determinável. Em suas formações primitivas, essa função era operada pela diferença conhecido/desconhecido [vertraut/unvertraut], no que a religião matinha ainda algum parentesco longínquo com o mito. Após a aquisição evolutiva representada pelo sacerdócio (Luhmann, 1989a, pp. 270ss.), a função da religião passou a ser operada pela forma imanência/transcendência, como código especificamente religioso. As religiōes de salvação originaram-se sob as pressões de reivindicações éticas e morais, pois já não contavam com a magia para mediar a relação entre o crente e seu deus - e, justamente por essa razão, firmaram-se nas sociedades estratificadas, pois se tratava de legitimar o estamento sacerdotal de forma paralela às diferenças de riqueza e ao centralismo político típico dessas sociedades: "A questão quanto à justificação de desigualdades manifestas não é tratada como uma questão puramente ética; ela é parte de uma questão teológica, cosmológica e metafísica quanto à constituição do mundo como um todo. Essa ordem do mundo é pensada de tal modo que os aspectos ontico e normativo se fundem um no outro" (Habermas, 1981, pp. 281-282). Tratava-se de atribuir um sentido transcendente ao curso do mundo diante do injustificado sofrimento intramundano; era preciso desvalorizar profundamente o mundo social em nome do mundo situado para além dele.

O ponto de partida de Weber é investigar o desenvolvimento típico-ideal de éticas religiosas de negação do mundo, não obstante nosso interesse pela Consideração intermediária esteja mais relacionado com a caracterização que ela fornece das tensões entre âmbitos religiosos e não religiosos em um processo de diferenciação social. Note-se bem: recuperamos elementos para uma teoria da diferenciação social (e não funcional) em Weber. ${ }^{3}$ Não pretendemos sustentar que a diferenciação de esferas de valor equivale à diferenciação de sistemas funcionais, considerando-se essencialmente a diferença (já mencionada no início deste artigo) entre fundar a teoria social na categoria da ação (Weber) ou na categoria da comunicação (Luhmann). Pois bem, Weber analisa em Consideração intermediária como éticas de rejeição do mundo oscilam entre dois po- los típico-ideais: a contemplação mística e a ascese ativa. Essa, pela compreensão que o crente tem de si mesmo como um instrumento para a obra divina; aquela pela posse contemplativa do sagrado; a ascese ativa representa um agir, a outra representa um possuir (Weber, 1988b, p. 538). Mas, não obstante tais diferenças, "Ambas condenam o mundo social por fim a uma absoluta falta de sentido ou pelo menos à sua completa incompatibilidade com os desígnios de deus" (Idem, p. 552). A ascese ativa tipicamente ocidental, por sua vez, pôde se revelar historicamente em duas direções distintas de negação do mundo: de um lado, a negação referenciada ao mundo exterior cujo tipo ideal pode ser encontrado no monasticismo católico medieval; de outro, o calvinismo ascético em sua afinidade com uma ética da vocação profissional na qual coincidem mais perfeitamente negação e dominação do mundo (cf. Schluchter, 1981, pp. 156-166).

Weber cuidará de explicar, do ponto de vista da religião, as tensões provocadas pelos valores laicos do mundo moderno (as esferas econômica, política, estética, erótica e intelectual), a fim de identificar como se comportam rejeições ascéticas e místicas do mundo. Não é o caso de recompor aqui os pormenores das tensões entre a religião e as demais esferas de valor. ${ }^{4}$ Para nossos fins, o elemento comparativo pertinente à sociologia da religião é menos importante do que o componente analítico que nos permite identificar, para uma teoria geral da sociedade, a emergência de lógicas sociais em processo de desentranhamento de uma sociedade religiosa e que, a partir de então, passam a se mover seguindo motricidades próprias:

Pois a racionalização e a sublimação consciente das relações das pessoas com as diferentes esferas de posse de bens exteriores e interiores, religiosos e mundanos, empurram a isto: a tomar consciência das legalidades próprias internas às esferas individuais em suas consequências, de maneira que [essas esferas] se permitem encontrar naquelas tensóes mútuas que permaneceram ocultas à simplicidade e à ingenuidade das relações primitivas do homem com o mundo exterior (Weber, 1988b, pp. 541-542, grifos no original). 
As tensões identificáveis entre diferentes esferas de valor que possuem legalidades próprias $[E i-$ gengesetzlichkeiten] haviam permanecido latentes em função de uma integração moral, cosmológica e religiosa da ordem social, assegurada pelo menos até o Renascimento. O desencantamento do mundo liberou legalidades próprias que muitas vezes estabelecem relações de tensionamento mútuo e que, por sua vez, não se permitem reconduzir a um processo monolítico de racionalização (cf. Raulet, 2004, pp. 79-91; Pierucci, 2003, especialmente cap. 10). ${ }^{5}$ De seu ponto de vista, a religião reage às esferas de valor que dela se pretendem diferenciar com base em sua própria Eigengesetzlichkeit: reage reforçando a rejeição do mundo terreno; acentuando a tensão entre transcendência e imanência, atribuindo sentido à última pela referência à primeira. A religião, quando confrontada pela autonomização da economia, da política, da cultura etc. não encontra uma solução de compromisso. Ao contrário, e para voltarmos à terminologia luhmanniana, reage radicalizando sua codificação binária imanêncialtranscendência.

A Consideração intermediária ajuda a entender o argumento luhmanniano de que a religião se diferencia por reação, uma vez que Weber analisa as tensões entre a religião e as demais esferas de valores mundanos (entre o lado religioso e o lado não religioso da sociedade), e não as tensões reciprocamente estabelecidas entre as múltiplas esferas de valor. A Consideração intermediária permite ilustrar uma impressão muito presente em Luhmann: a de que os sistemas sociais não estão em repouso e não preservam simetria harmônica entre si (como imaginam alguns críticos); a diferenciação funcional não cruza uma linha de chegada. Cada sistema social está sempre lutando para manter sua fronteira sistema/ambiente; está sempre sobre pressão do excesso de complexidade que o ambiente representa para ele. Diante dessa pressão, a única saída para cada sistema funcional é intensificar seu fechamento operacional, fortalecendo sua fronteira com o ambiente e preservando sua autopoiese. Claro, sistemas autopoiéticos somente conseguem reduzir complexidade do ambiente com ganho de complexidade interna. A especificidade histórica da diferenciação funcional da religião - mas também o problema que ela representa - não está apenas em configurar um processo reativo; está sobretudo no fato de que esse processo culminou na privatização da experiência religiosa (o que Luhmann define como secularização da sociedade):

Podemos definir secularização como a relevância socioestrutural da privatização da decisão religiosa. Com isso não se postula em última instância a perda de função ou de significado da religião, teórica ou conceitualmente. [...] O conceito descreve ao contrário um desenvolvimento estrutural historicamente apreensível para o sistema da sociedade, na medida em que tem efeitos sobre o sistema religioso e seu ambiente (Luhmann, 1977, pp. 232-233, grifo no original).

Os outros sistemas funcionais têm de assegurar sua autonomia contra os controles religiosos [...]. A religião mesma não consegue reagir adequadamente [a isso]" (Idem, 1989a, p. 291).

Em um mundo caracterizado pela multiplicação de lógicas comunicativas próprias que não permitem recobrar um fundamento religioso unitário para a condução da vida, a religião teve de se exilar no íntimo do indivíduo. Concluída a passagem à sociedade funcionalmente diferenciada, esta reação da religião pode ser considerada "inadequada", por assim dizer, porque implica transferir a poiese de sentido religioso da esfera social, comunicativa, para a esfera individual da consciência, da fé. A próxima seção é dedicada ao desdobramento deste argumento.

\section{A privatização da experiência religiosa}

No Ocidente, o último momento em que uma visão de mundo unitária e totalizante foi capaz de ditar a condução da vida em todos os âmbitos simbólicos que hoje reconhecemos como sistemas funcionalmente diferenciados talvez possa ser localizado apenas na Idade Média anterior à Reforma Religiosa. Como se sabe, um dos principais fatores que contribuíram para a fragmentação da ordenação cosmológica e moral-religiosa da sociedade 
feudal foi a difusão da imprensa - e, mais especificamente, a tradução da Bíblia. Trata-se, evidentemente, de um processo histórico extremamente largo que não pretendemos recompor neste artigo; ao contrário, adotaremos a tradução da Bíblia como fenômeno catalisador da privatização da experiência religiosa.

Até o século XVI, havia apenas uma versão do texto sagrado e uma verdade religiosa. Isso somente era possível em uma sociedade estratificada em que o acesso ao texto sagrado era privilégio estamental, apoiado em mecanismos de controle de sua interpretação (Hill, 2003, p. 26). O controle hermenêutico do texto bíblico era assegurado pela censura, pela catequese, pelos monopólios de edição da Bíblia e pelas homilias (textos exegéticos que explicavam o teor das escrituras de maneira a reforçar a autoridade da igreja católica). Tais mecanismos não assegurariam uma interpretação unívoca do texto bíblico a partir de meados do século XVII:

A imprensa possibilita um volume de reprodução que, por sua vez, permite uma distribuição mercadológica, ou seja, a produção do texto se orienta pela demanda e com isso se desacopla do próprio interesse do escritor ou daquele que encomendava o texto ao escritor (Luhmann, 1997, p. 292). ${ }^{6}$

Com efeito, se a imprensa surge em um mundo religioso, mas se orienta pela busca do lucro, a mercadoria mais promissora para as primeiras gráficas e editoras é justamente a Bíblia. A difusão da imprensa e a tradução da Bíblia tornaram sua leitura cotidiana um hábito prosaico e o letramento ocidental fora em grande medida conduzido pela leitura da Bíblia. Mas a difusão da imprensa não deve ser restrita à dimensão puramente mercantil do fato (razoavelmente trivial) de que os livros são mercadorias como todas as outras. A China, por exemplo, possuía tanto o comércio como a imprensa. O específico do Ocidente foi combinar a difusão mercadológica da imprensa com revolução religiosa - "O único problema é que os leitores, quando podem ler a Bíblia, podem ler também outros textos"; "Quem pode ler a Bíblia, pode também ler panfletos de polêmica religiosa, jornais, ro- mances" (Idem, pp. 292 e 729). A partir daí estava aberto o acesso direto, difuso e descentralizado ao texto sagrado da tradição cristã, a verdade do texto religioso estava disponível para quem soubesse ler. Eis o ponto de partida para divergências exegéticas:

A capacidade individual de pôr à prova e refletir sobre as imposiçōes decorrentes da fé, ligada à difusão do domínio da escrita, torna-se um problema apenas com a imprensa e, do lado protestante, conduz a uma alienação mais intensa (crença nas escrituras - se não estivesse escrito, não se acreditaria - e necessidade de uma organização eclesiástica) e a uma internalização mais intensa da fé como experiência própria e convencimento próprio de cada um em sua confissão intima (Luhmann, 2000b, p. 205, grifo nosso).

Nesta seção, uma breve referência a $A$ ética protestante e o "espirito" do capitalismo nos ajudará a ilustrar o processo de diferenciação funcional da religião como privatização da experiência religiosa. ${ }^{7}$ Por óbvio, não é o caso de recompor toda a articulação interna de uma obra tão rica quanto esta, até porque não pretendemos investigar quão efetiva fora a doutrina da predestinação na orientação da conduta dos puritanos ou calvinistas, nem sua relação com a construção de uma ética do trabalho profissional. Nosso recurso a Weber destina-se exclusivamente a ilustrar como a doutrina da predestinação representa um passo importante na privatização da experiência religiosa. Na doutrina da predestinação, o protestante tem de estar absolutamente convicto de que sua alma está salva e, não obstante, tem de exteriorizar seu estado espiritual em ações intramundanas. Não basta apenas agir, da mesma forma como não é possível apenas crer e permanecer inerte ao mundo: é preciso estar convicto para agir no mundo; é o crente que, em sua consciência, opera a remissão da imanência a um sentido transcendente. Recuperemos parte do argumento d'A ética protestante:

No presente, com nossas instituiçōes políticas, jurídicas e comerciais, com as formas de gestão empresarial e a estrutura que é própria da 
nossa economia, esse "espírito" do capitalismo poderia ser entendido como puro produto de uma adaptação, conforme já se disse. A ordem econômica capitalista precisa dessa entrega de si à "vocação" de ganhar dinheiro: ela é um modo de se comportar com os bens exteriores que é tão adequada àquela estrutura, que está ligada tão de perto às condiçôes de vitória na luta econômica pela existência, que de fato hoje não há mais que se falar de uma conexão necessária entre essa conduta de vida "crematista" e alguma "visão de mundo" unitária. É que ela não precisa mais se apoiar no aval de qualquer força religiosa e, se é que a influência das normas eclesiásticas na vida econômica ainda se faz sentir, ela é sentida como obstáculo análogo à regulamentação da economia pelo Estado. [...] o capitalismo moderno, agora vitorioso, já se emancipou dos antigos suportes" (Weber, 2004, p. 64, grifo no original; sublinhado acrescido).

Esta passagem remete às afinidades eletivas entre uma ética especificamente religiosa e uma ética profissional nascente (Löwy, 2004, pp. 93-103). A preocupação de Weber é relatar, pela síntese conceitual altamente elaborada que lhe é característica, um processo histórico bastante largo. A articulação entre a ética protestante e aquilo que se pôde chamar "espírito" do capitalismo ocorrera apenas remotamente, como afinidade eletiva entre religião, moral e economia. A afinidade eletiva é a formulação por meio da qual Weber rastreia o parentesco vestigial entre o desenvolvimento da vocação religiosa puritana e a nascente ética profissional, que somente muito tempo depois seria associada às formas de vida burguesas.

Para nossos propósitos, o importante é identificar como o protestantismo aprofunda a privatização da experiência religiosa. A Reforma Religiosa provoca uma diferenciação interna entre protestantismo e catolicismo e permite uma especialização da função precípua da religião (negação do mundo), cujo ponto nodal é sua des-ritualização (Luhmann, 1977, p. 108; Weber, 2004, p. 106). De fato, os sacramentos católicos podem ser vistos como reminiscências mágicas, especialmente se considerarmos, por exemplo, o rito da transubstanciação - o milagre de tornar deus presente, a cargo do padre. O protestantismo ascético consuma a diferenciação funcional da religião (pelo menos no que diz respeito ao cristianismo ocidental), como des-ritualização da fé. Por isso Weber argumenta que o "puritano genuíno" vive na solidão de sua íntima convicção religiosa e, assim, constantemente imerso em um "sentimento de inaudita solidão interior", pois a doutrina da predestinação lhe cobra "a forma mais extremada de exclusividade da confiança em Deus” (Weber, 2004, pp. 95-96).

No arcabouço luhmanniano, é possível dizer que a Reforma Religiosa e o desenvolvimento do protestantismo significaram passos de diferenciação funcional da religião, porque especializaram a função que a religião desempenha para a sociedade: a atribuição de sentido à imanência pelo recurso à transcendência. É claro que a diferenciação funcional da religião não se confunde com a Reforma nem com o protestantismo, pois ela descreve o processo histórico mais amplo pelo qual a religião deixara de se identificar com a moral, a política, a economia e as demais esferas sociais. A religião funcionalmente diferenciada se especializa como negação exclusivamente religiosa do mundo e, nessa medida, interior ao individuo. Tudo se passa como se o mandamento do monasticismo católico medieval ora et labora fosse especializado funcionalmente pela Reforma: em uma primeira "jornada de diferenciação", o protestantismo assume o mandamento monástico, mas o retira do monastério e o insere em cada protestante; em uma segunda "jornada de diferenciação", a ética da vocação profissional está tão solidamente entranhada na esfera econômica que deixa de depender de um fundamento religioso - há, por assim dizer, uma ruptura do mandamento medieval: ora para a religião; labora para a economia (Schluchter, 1981, p. 150). A partir daí, a religião torna-se uma questão individual, e é por isso que a diferenciação funcional da religião pode ser expressa como privatização da experiência religiosa:

Privatização significa, para o âmbito religioso, que a participação na comunicação espiritual (igreja), assim como a crença na fé, tornou-se matéria de decisão individual; que somente po- 
de-se esperar religiosidade sobre o fundamento de uma decisão individual e que esse fenômeno se tornou consciente. Enquanto o não acreditar era, antes disso, matéria privada, agora a crença torna-se matéria privada (Luhmann, 1977, pp. 238-239).

As consequências para que, nestas condições, a religião mantenha sua diferença sistema/ambiente não são de somenos importância. À definição de sistema autopoiético que avançamos inicialmente, é preciso acrescer que de forma geral (e contrariando as rotinas expositivas adotadas por luhmannianos mais ortodoxos) um sistema autopoiético apresenta três características essenciais: (i) dispõe de um meio de comunicação simbolicamente generalizado que estrutura suas operaçôes (o poder para a política; o dinheiro para a economia; a juridicidade - ou poder juridicamente regulado - para o direito; a verdade para a ciência; o amor para as relaçóes pessoais etc.); (ii) está imbricado em outros sistemas por meio de acoplamentos estruturais (a constituição para as relaçôes entre política e direito; a propriedade privada para direito e economia; a inovação tecnológica para economia e ciência; o orçamento público para política e economia; e assim por diante); e (iii) tem regras autônomas de inclusão e exclusão para condicionar a participação dos indivíduos (as consciências empíricas) nas suas operaçôes. É claro que a teoria de sistemas sociais não é ingenuamente construída como um quebra-cabeça de peças homogêneas. Existem sistemas que não dispõem de meios de comunicação simbolicamente generalizados, por exemplo, a educação. Mas, de um lado, ela compensa essa lacuna com fortes acoplamentos estruturais com a política e a economia, e, de outro, com regras rígidas de inclusão e exclusão. Ou seja: historicamente considerados, os sistemas precisam dispor de algum grau de institucionalização social, o que é obtido pelos diversos sistemas em diversa medida e por diversas formas.

Ora, para que a teoria de sistemas sociais continue considerando a religiáo um sistema autopoiético tal como os demais, a questão parece ser um pouco mais séria. Ao que tudo indica, a religião: (i) não conta com um meio de comunicação simbolicamente generalizado especificamente religioso; (ii) não está estruturalmente acoplada aos demais sistemas da sociedade; e (iii) não conta com regras socialmente estabelecidas de inclusão e exclusão (isto é, estabelecidas para além do nível das consciências empíricas).

As dificuldades enfrentadas na discussão quanto à possibilidade de que a fé [Glaube] seja considerada o meio de comunicação simbolicamente generalizado do sistema religioso são reconhecidas sem reservas (cf. Schlögl, 2001, pp. 27ss.; Dinkel, 2001, p. 57). Aqui é preciso recuperar, para a correta compreensão do funcionamento social dos meios de comunicação simbolicamente generalizados, a relação entre ação e comunicação na teoria de sistemas sociais. Não obstante a comunicação seja a operação genuinamente social na teoria de sistemas (Luhmann, 1997, p. 81), é indispensável apreendê-la por meio de processos de adjudicação ou de atribuição [Zurechnung] de cursos de ação, por meio dos quais os sistemas sociais logram condicionar a reprodução de suas próprias operaçôes. Por mais que a comunicação seja o processo elementar a partir do qual os sistemas sociais se permitem emergir, há que se considerar que eles somente conseguem controlar suas operações se forem capazes de reduzir sua própria complexidade. A construção da ação, portanto, é o artefato indispensável por meio do qual o sistema consegue reduzir sua complexidade interna e, com isso, controlar suas operaçōes comunicativas: "Os sistemas sociais, portanto, não são construídos a partir de açōes, como se essas açóes fossem produzidas por força da constituição orgânico-psíquica da pessoa e pudessem existir por si; eles são decompostos em ações e ganham, por meio dessa redução, fundamentos para conexão a novos processos comunicativos" (Idem, 1984, p. 193). A ação é construída nos sistemas sociais por meio da diferença ação/vivência [Handlung/Erleben]: tem-se ação quando a comunicação acentua a seleção de uma informação interna ao sistema; tem-se vivência quando a comunicação acentua o efeito que a transmissão [Mitteilung] de uma informação provoca - no próprio sistema e em seu ambiente. ${ }^{8}$

Os meios de comunicação simbolicamente generalizados são tecnologias que ajudam na transcriçãao da comunicação como ação: oferecem scripts de atuação estandardizados, padrões comunicativos 
institucionalizados e disponibilizados pela sociedade para a orientação do comportamento humano (Idem, 1974; 1997, pp. 316-396). Por exemplo, no caso da verdade, não se trata de uma noção axiomática última; significa simplesmente que o trabalho científico deve prestar contas de seus pressupostos e apresentar conclusões fundamentadas. No caso do poder, as operações políticas (decisões coletivamente vinculantes) devem ser tomadas com base em um conjunto de regras decisórias - sem invocar, com isso, qualquer crítica ou apologia dos poderes políticos efetivamente estabelecidos. Pois bem: a fé poderia ser considerada uma tecnologia comunicativa capaz de coordenar o comportamento humano na mesma medida em que o fazem o dinheiro, o poder, a verdade ou até mesmo o amor nas relações íntimas?

Como o próprio Luhmann reconhece, a fé, diferentemente dos típicos meios de comunicação simbolicamente generalizados, não permite diferenciar socialmente a ação individual internamente motivada da vivência externamente motivada (Idem, 1977, pp. 134-135; 2000b, pp. 205-206). Essa diferença remanesce acessível apenas para o indivíduo. É claro que isso não implica a redução da religião a um mero fenômeno da consciência: ela se objetiva efetivamente como comunicação sempre que o comportamento individual seja determinado religiosamente (Idem, 2000b, p. 40). O problema é que o engajamento da consciência não é aferível por um observador de segunda ordem. Dito de outra maneira: a comunicação religiosa depende muito estreitamente do engajamento das consciências empíricas; para que a comunicação religiosa ocorra como fenômeno social, ela requisita toda a complexidade disponível da consciência - e isso porque a religião está orientada à integralidade do indivíduo (Idem, 1989a, p. 345). A fé religiosa exige uma interpenetração altamente inelástica entre comunicação e consciência - o que nos autoriza a questionar a validade da diferença sistema/ambiente para a religião.

A indisponibilidade de um meio de comunicação simbolicamente generalizado é agravada porque a religião não está estruturalmente acoplada aos demais sistemas. De fato, os acoplamentos estruturais constituem o desdobramento necessário à autopoiese. Acoplamentos estruturais são estruturas redutoras de complexidade disponibilizadas para mais de um sistema simultaneamente. Elas estabelecem filtros de input e output entre sistemas e estabilizam dependências recíprocas. Portanto, a dinâmica histórica de diferenciação dos diferentes sistemas funcionais tem de ser compreendida à luz dos correlatos acoplamentos estruturais que permitiram que os sistemas sociais se tornassem autopoiéticos. Como vimos, a diferenciação funcional da religião, impulsionada como reação à diferenciação funcional dos âmbitos não religiosos da sociedade, foi responsável pela privatização da experiência religiosa, o que exige reconhecer que, do ponto de vista da sociedade, a comunicação religiosa não consegue se estabelecer sem o engajamento das consciências empíricas justamente porque a religião não dispõe de acoplamentos estruturais com outros sistemas sociais, como reconhece o próprio Luhmann (1997, p. 787).

Como consequência, por fim, o acesso à religião depende exclusivamente de uma decisão individual - a religião não regula socialmente (isto é, para a sociedade) as regras de inclusão e exclusão, pois elas dependem única e exclusivamente da vontade do indivíduo (Idem, 1989a, p. 349; 2000b, pp. 304-305). ${ }^{9}$ Diferentemente do acesso ao mercado, às instituiçõos jurídicas, à educação e à formação da vontade política, a religião não depende de um teste de pré-requisitos sociais. Basta ir à igreja. Mas, para tanto, é indispensável primeiramente querer ir à igreja. E, uma vez na igreja, é preciso disponibilizar toda a complexidade da consciência à reprodução da comunicação religiosa - é preciso engajá-la religiosamente; mas este engajamento somente pode ser uma operação da própria consciência, e não da sociedade.

Em conclusão, se a caracterização de um sistema autopoiético depende de sua capacidade em manter uma diferença sistema/ambiente específica, a religião - sem um meio de comunicação simbolicamente generalizado especificamente religioso, sem acoplamentos estruturais com outros sistemas funcionais da sociedade e sem a capacidade de fixar critérios próprios de inclusão e exclusão - não deve ser considerada um sistema autopoiético tal como os demais. A diferença religião/ambiente até 
poderia ser preservada na relação da religião com a sociedade, mas não em sua relação com as consciências empíricas. Partindo da diferença religiāol sociedade (estabelecida naquele processo em que os âmbitos não religiosos da sociedade se fecharam operacionalmente em oposição a uma sociedade integralmente religiosa), a religião encontra extremas dificuldades para manter a diferença religião/consciência, pois a reprodução da comunicação religiosa tem por pressuposto uma operação da consciência: a participação dos sistemas psíquicos com base na fé. Nessas condições, torna-se impossível à religião sustentar sua fronteira sistema/ambiente a ponto de manter a diferença entre comunicação e consciência e, com isso, assegurar sua reprodução autopoiética como autêntico sistema funcional operativamente fechado.

\section{A religião como código binário}

A religião ocupa uma posição central no processo de diferenciação funcional da sociedade, mas, contrariamente ao que se verificou em outras esferas sociais, tudo indica que ela não evoluiu para um autêntico sistema autopoiético. Vimos que a diferenciação funcional da religião é peculiar na medida em que os demais sistemas funcionais estabeleceram suas respectivas diferenças sistema/ambiente (política/sociedade, economia/sociedade, direito/ sociedade etc.) ao se diferenciarem de uma sociedade inteiramente religiosa. Assim, a diferenciação funcional da religião - por reação à diferenciação dos demais âmbitos não religiosos - significou a migração da vivência religiosa para o âmbito da convicção interna do indivíduo. Ao fim e ao cabo, a sociedade funcionalmente diferenciada não tem como disciplinar a comunicação religiosa independentemente das consciências empíricas.

Nesta seção conclusiva, nossa tarefa é propor um pequeno reparo conceitual que ajuste a teoria de sistemas sociais à observação da religião sem abrir mão de suas premissas centrais: cuida-se de substituir a compreensão da religião como sistema por sua compreensão exclusivamente como o código binário.

À semelhança do que se passou com a religião, também a moral se caracteriza na sociedade fun- cionalmente diferenciada por dispor de um código binário: trata-se de operar reconhecimento e indiferença [Achtung/Mißachtung] como diferença eticamente manejável (Idem, 1989b, pp. 358-447). Historicamente consideradas, verifica-se uma coevolução entre religião e moral. O código reconhecimento/indiferença desenvolveu-se como segunda codificação aplicada sobre a religião com recurso à diferença originária bom/mau. $\mathrm{Na}$ origem, a moral, para lidar com seu próprio paradoxo ("a distinção bom/mau é boa?"), teve de recorrer à religião; da mesma forma como a religião, para resolver seu próprio paradoxo ("a distinção imanência/transcendência é transcendente ou imanente?"), teve de se moralizar (Idem, 1997, p. 243). Para tanto, há uma fórmula de contingência [Kontingenzformel] especial: deus. Todo sistema social recorre a fórmulas de contingência para se impor autolimitaçôes: são fórmulas programáticas autoimpostas, algo como um "princípio último" que condiciona as operaçōes do sistema. Tais fórmulas são históricas e específicas para as necessidades de cada sistema, por exemplo: perfeição, formação [Bildung] e capacidade de aprendizagem na educação; escassez na economia; a necessidade de limitação do objeto científico na ciência; equidade no direito; o bem-comum e, posteriormente, a legitimidade na política, e assim por diante (Idem, 2000a, p. 120, nota 50). É claro que tais fórmulas de contingência são semânticas históricas - e, como tais, não são efetivamente princípios normativos últimos, pelo menos para um observador de segunda ordem. Pois bem, a fórmula de contingência da religião é deus: ele realiza a transcendência na imanência e explica a presença do mal no mundo, mesmo sendo deus um deus bom (donde o problema da teodiceia) (Idem, 1987a, p. 253). Dessa forma, a orientação da conduta e da interação humana na sociedade feudal - se não em todas as suas facetas, pelo menos na imensa maioria delas - ocorria pela conjunção de duas estruturas simbólicas convergentes (quando não coincidentes): religião e moral. O que permitiu que, a partir dessa origem comum, elas se diferenciassem uma da outra?

O posicionamento diante do segredo (Idem, $1997,242 s s)$. Tanto a religião como a moral contavam com uma regra de não exceção: podiam ob- 
servar os dois lados da distinção que operavam, ao mesmo tempo em que vedavam qualquer hipótese de observação de segunda ordem - não havia a menor possibilidade de que a religião pudesse ser observada de um ponto de vista não religioso e a moral de um ponto de vista não moral. Enquanto a religião, para manter-se adstrita a uma regra de não exceção, exigia o segredo (o mistério, o incompreensível, o sagrado - que não se explica e que, por isso, exige fé); a moral, por sua vez, para se manter adstrita à mesma regra, tinha de repudiar o segredo em nome da publicidade. Isso fica muito claro no caso da moral quando observamos a constituição da opinião pública e, no caso da religião, quando recuperamos os transtornos causados pela tradução da Bíblia (cf., respectivamente, Koselleck, 1999; Hill, 2003).

Desde então, a moral é mobilizada socialmente como código, não tendo evoluído para um sistema autopoiético próprio. A moral permanece à disposição da sociedade funcionalmente diferenciada, mas apenas como critério de julgamento acerca do reconhecimento ou da indiferença com relação a pessoas ou grupos de pessoas, desempenhando uma espécie de função de alarme: ela aponta problemas localizados nos sistemas funcionalmente diferenciados que não podem ser resolvidos pelos meios de comunicação por eles empregados (Luhmann, 1997, p. 404). Os indivíduos manejam corriqueiramente argumentos e valores morais em inúmeras situaçôes, aceitam compromissos e mantêm a palavra empenhada ou mentem normalmente - em todos esses casos, a ação é orientada moralmente, embora não seja possível dizer que tais ações sejam operações realizadas por um sistema moral.

Tudo leva a crer que, à semelhança da moral, também a religião poderia ser caracterizada como código binário que não evoluiu para um sistema autopoiético propriamente dito: "A reação religiosamente determinada à progressiva diferenciação de sistemas funcionais transcorre um curso involutivo, e não evolutivo" (Idem, 1989a, p. 347).

Mas, considerada como código, preservaria a religião ainda alguma função relevante para a sociedade como um todo? Aqui é preciso separar as questôes: o fato de a religião não ser considerada um sistema autopoiético não diminui, em absoluto, sua importância na sociedade funcionalmente diferenciada. Tal como a moral, a religião ainda preserva uma função na sociedade contemporânea e orienta, em medida muito significativa, o comportamento individual. Por exemplo, na discussão parlamentar envolvendo temas como a eutanásia ou o aborto, a comunicação religiosa ou moral pode ser facilmente mobilizada para aumentar a complexidade da política e introduzir uma incerteza que não pode ser absorvida pelo poder enquanto meio de comunicação simbolicamente generalizado, codificado pela diferença governo/oposição. E se é evidente que uma decisão será tomada (aprovar ou rejeitar uma lei que permita o aborto), ela será tomada por maioria de votos, contabilizando os votos do governo e da oposição - e não dos padres, pastores ou ativistas. Mas governo e oposição poderão considerar argumentos religiosos e morais para votarem contra ou a favor do aborto. Se a religião depende da adesão individual, é forçoso reconhecer que essa adesão é maciça. E, poderíamos arriscar, talvez a força da religiāo esteja justamente no fato de que, como código binário, ela é capaz de transmitir irritação aos demais sistemas sociais de maneira transversal às suas respectivas diferenças sistema/ambiente.

Além disso, há um último aspecto a ser considerado e que diz respeito à função clássica que a religião desempenha para a sociedade como um todo: dotar de sentido o plano da imanência remetendo-o à transcendência (Idem, 1989a, p. 349-350). A função clássica da religião preserva sua relevância para a sociedade contemporânea na medida em que o código religioso permita compensar, "espiritualmente", a exclusão cumulativa dos demais sistemas funcionais da sociedade (o acesso precário aos cuidados mínimos na primeira infância; a repetência escolar que provoca a dificuldade de colocação profissional e que acarreta diminuta capacidade de participação política, estética e cultural etc.) - com a finalidade de evitar que o fracasso seja imputado exclusivamente ao indivíduo (Karle, 2001, p. 113). Trata-se de disponibilizar para o indivíduo a liberdade de tomar uma decisão pela qual ele é o único responsável, compensando, em alguma medida e em um nível 
muito baixo de institucionalização simbólica, a exclusão cumulativa que ele experimenta em outros sistemas sociais.

\section{Notas}

1 Cf., ilustrativamente, Luhmann (2006, 2005). Para uma recepção crítica, cf. Bachur (2010).

2 Cf., para uma crítica a partir da teologia, Scholz, (1982, pp. 181). Cf., mais recentemente, Pollack (2001, pp. 5-22), Beyer (2001, pp. 46-55) e Sløk (2006, pp. 327-345).

3 Cf., nesse sentido, Luhmann (1989a, pp. 259ss (mantidas intactas as ressalvas do próprio Luhmann neste ponto); Schwinn (2001, pp. 154-207); Kneer (2004, p. 30); e Schluchter (1981, p. 74).

4 Para uma exposição mais longa (mas sem muita criatividade) sobre a diferenciação de cada esfera de valor, cf. Schwinn (2001, pp. 154-207).

5 É nesse contexto que emerge o argumento da perda de sentido relacionada com o desencantamento do mundo, pois o "politeísmo dos valores", um politeísmo de valores intramundanos, erodiu aquilo que uma vez a religião chegou a garantir: uma autêntica Weltanschauung unitária para a ordem social feudal e pré-moderna, sólida e suficientemente coesa a ponto de determinar em grande medida a condução da vida cotidiana (cf. Weber, 1988a, pp. 506-507; e Pierucci, 2003, pp. 139-140).

6 Essa explicação é muito frequente na literatura - cf. Eisenstein (2005, p. 689); e Febvre e Martin, 1976, p. 249: "Não se deve perder de vista o seguinte fato: o editor e o vendedor de livros trabalhavam sobre tudo e desde o começo buscando o lucro".

7 Cf., para a relação entre o protestantismo e a diferenciação funcional da religião, Karle (2001, pp. 102106). Para a relação entre imprensa e Reforma protestante, cf. Eisenstein (2005, pp. 303-304), Febvre e Martin (1976, p. 288), Dinkel (2001, p. 62).

8 A relação entre ação e comunicação constitui um dos pontos mais sofisticados da teoria social de Luhmann, e que aqui teremos condições de mobilizar apenas pontualmente. Cf., neste ponto, Luhmann (1978) e Heidenescher (1992).

9 "A determinação mais lata do conceito de secularização implica: que se tornou afinal matéria de decisão individual engajar-se religiosamente, e até mesmo: em qual religião” (Luhmann, 2000b, p. 289).

\section{BIBLIOGRAFIA}

BACHUR, J. P. (2010), As portas do labirinto: para uma recepção crítica da teoria social de Niklas Luhmann. Rio de Janeiro, Azougue.

BEYER, Peter. (2001), "Religion as Communication in Niklas Luhmann's Die Gesellschaft der Gesellschaft”. Soziale Systeme. Zeitschrift für Soziologische Theorie, 7 (1): 46-55.

DINKEL, Christoph. (2001), "Glaube als symbolisch generalisiertes Kommunikationsmedium”. Soziale Systeme. Zeitschrift für Soziologische Theorie, 7 (1): 56-70.

EISENSTEIN, Elizabeth. (2005), The printing press as an agent of change: communications and cultural transformations in Early-Modern Europe. Nova York, Cambridge University Press.

FEBVRE, Lucien \& MARTIN, Henri-Jean. (1976), The coming of the book: the impact of printing 1450-1800. Tradução de David Gerard. Londres/Nova York, Verso.

HABERMAS, Jürgen. (1981), Theorie des kommunikativen Handelns. Frankfurt, Suhrkamp.

HEIDENESCHER, Mathias. (1992), "Zurechnung als soziologische Kategorie. Zu Luhmanns Verständnis von Handlung als Systemleistung”. Zeitschrift für Soziologie, 21 (6): 440-455.

HILL, Christopher. (2003), A biblia inglesa e as revoluções do século XVII. Tradução de Cynthia Marques. Rio de Janeiro, Civilização Brasileira. KARLE, Isolde. (2001), "Funktionale Differenzierung und Exklusion als Herausforderung und Chance für Religion und Kirche". Soziale Systeme. Zeitschrift für Soziologische Theorie, 7 (1):100-117.

KOSELLECK, Reinhart. (1999), Critica e crise: uma contribuição à patogênese do mundo burguês. Tradução de Luciana Villas-Boas Castelo-Branco. Rio de Janeiro, Eduerj/Contraponto.

KNEER, Georg. (2004), "Differenzierung bei Luhmann und Bourdieu. Ein Theorienvergleich", in A. Nassehi e G. Nollman (orgs.), Bourdieu und Luhmann: ein Theorienvergleich, Frankfurt, Suhrkamp.

LÖWY, Michael. (2004), "Le concept d'affinité élective chez Max Weber". Archives de Sciences Sociales des Religions, 127: 93-103. 
LUHMANN, Niklas. (1974), "Einführende Bemerkungen zu einer Theorie symbolisch generalisierter Kommunikationsmedien", in Soziologische Aufklärung, 5 ed., Wiesbaden, VS, vol. 2, pp. 212-240.

. (1977), Funktion der Religion. Frankfurt, Suhrkamp.

(1978), "Erleben und Handeln", in Soziologische Aufklärung, 4 ed., Wiesbaden, VS, vol. 3, pp. 77-92.

. (1981), "Die Unwahrscheinlichkeit der

Kommunikation", in Soziologische Aufklärung, 4 ed., Wiesbaden, VS, vol. 3, pp. 29-40.

. (1984), Soziale Systeme: Grundriß einer allgemeinen Theorie. Frankfurt: Suhrkamp.

(1986), "Intersubjektivität oder

Kommunikation: Unterschiedliche Ausgangspunkte soziologischer Theoriebildung", in Soziologische Aufklärung, 2 ed., Wiesbaden, VS, vol. 6, pp. 162-179.

. (1987a), "Die Unterscheidung Gottes", in Soziologische Aufklärung, 3 ed., Wiesbaden, VS, vol. 4, pp. 250-268.

. (1987b), "Was ist Kommunikation?", in Soziologische Aufklärung, 2 ed., Wiesbaden, VS, vol. 6, pp. 109-120.

(1989a), "Die Ausdifferenzierung der Religion", in Gesellschaftsstruktur und Semantik. Studien zur Wissenssoziologie der modernen Gesellschaft, Frankfurt, Suhrkamp, vol. 3, pp. 259-357.

(1989b), "Ethik als Reflexionstheorie der Moral", in Gesellschaftsstruktur und Semantik. Studien zur Wissensoziologie der modernen Gesellschaft, Frankfurt, Suhrkamp, vol. 3. (1997), Die Gesellschaft der Gesellschaft. Frankfurt, Suhrkamp.

. (2000a), Die Politik der Gesellschaft. Frankfurt, Suhrkamp. (2000b), Die Religion der Gesellschaft. Frankfurt, Suhrkamp. . (2005), Einführung in die Theorie der Gesellschaft. Heidelberg, Carl-Auer-System (org. Dirk Baecker). . (2006), Einführung in die Systemtheorie. 3 ed, Heidelberg, Carl-Auer-System (org. Dirk Baecker).
PIERUCCI, Antônio Flávio. (2003), O desencantamento do mundo: todos os passos do conceito em Max Weber. São Paulo, Editora 34.

POLLACK, Detlef. (2001), "Probleme der funktionalen Religionstheorie Niklas Luhmanns". Soziale Systeme. Zeitschrift für Soziologische Theorie, 7 (1): 5-22.

RAULET, Gerard. (2004), "Rationalisation et pluralité des rationalités". Archives de Sciences Sociales de Religions, 127: 79-91.

SCHWINN, Thomas. (2001), Differenzierung ohne Gesellschaft. Umstellung eines soziologischen Konzepts. Weilerwist, Velbrück Wissenschaft.

SCHLÖGL, Rudolf. (2001), "Historiker, Max Weber und Niklas Luhmann. Zum schwierigen (aber möglicherweise produktiven) Verhältnis von Geschichtswissenschaft und Systemtheorie”. Soziale Systeme. Zeitschrift für Soziologische Theorie, 7 (1): 23-45.

SCHLUCHTER, Wolfgang. (1981), The rise of Western rationalism: Max Weber's developmental history. Tradução de Guenther Roth. Berkeley/ Los Angeles, California University Press.

SCHOLZ, Frithard. (1982), Freiheit als Indifferenz. Alteuropäische Probleme mit der Systemtheorie Niklas Luhmanns. Frankfurt, Suhrkamp.

SLØK, Camila. (2006), "Niklas Luhmann's ambiguity towards religion". Soziale Systeme. Zeitschrift für Soziologische Theorie, 11 (2): $327-$ 345.

WEBER, Max. (1980 [1922]), Wirtschaft und Gesellschaft. 5 ed. Tübingen, Mohr Siebeck (org. J. Winckelmann). (1988a), "Der Sinn der "Wertfreiheit" der soziologischen und ökonomischen Wissenschaften", in Gesammelte Aufätze zur Wissenschaftslehre, 7 ed., Tübingen, J. C. B. Mohr (Paul Siebeck).

(1988b), “Zwischenbetrachtung: Theorie der Stufen und Richtungen religiöser Weltablehnung" in Gesammelte Aufsätzse zur Religionssoziologie, 9 ed., Tübingen, J. C. Mohr (Paul Siebeck), vol. 1. (2004), A ética protestante e o "espírito" do capitalismo. Tradução de José Marcos Mariani de Macedo. São Paulo, Companhia das Letras (ed. A. F. Pierucci. 


\section{A DIFERENCIAÇÃO FUNCIONAL DA RELIGIÃO NA TEORIA SOCIAL DE NIKLAS LUHMANN}

\author{
João Paulo Bachur
}

Palavras-Chave: Niklas Luhmann; Max Weber; Religião; Teoria de sistemas sociais; Diferenciação funcional.

O objeto deste artigo é investigar o lugar da religião na teoria de sistemas sociais de Luhmann com a finalidade de destacar algumas de suas ambiguidades e contradições internas. A especificidade da religião está no fato de que a participação na comunicação religiosa depende muito estreitamente do engajamento da consciência por intermédio da fé, o que dificulta a manutenção de sua fronteira sistema/ ambiente. Apresentamos a religião como caso específico de diferenciação funcional que ocorre por reação à diferenciação dos sistemas não religiosos da sociedade e como privatização da experiência religiosa. A sociologia de Weber é utilizada para ilustrar historicamente nosso argumento. Ao final, sugerimos um breve reparo conceitual capaz de adaptar a teoria de sistemas sociais à observação do fenômeno religioso na sociedade contemporânea.

\section{TUE FUNCTIONAL DIFFERENTIATION OF RELIGION IN THE SOCIAL THEORY OF NIKLAS LUHMANN}

\author{
João Paulo Bachur
}

Keywords: Niklas Luhmann; Max Weber; Religion; Social systems theory; Functional differentiation.

The purpose of this paper is to address religion in the framework of Luhmann's systems theory in order to identify some of its ambiguities and internal contradictions. The specificity of religion lays in the fact that taking part in religious communication depends rigidly on the actual engagement of consciousness through faith, what diminishes its capability of preserving its system/environment difference. We present religion as a specific case for functional differentiation because it takes place as a reaction against the functional differentiation of nonreligious systems of society and as some privatization of the religious experience. We refer to the sociology of Weber in order to illustrate historically our argumentation. In conclusion, we provide a brief conceptual adjustment capable of suiting the systems theory to the observation of religious phenomena in the contemporary society.

\section{LA DIFFÉRENCIATION FONCTIONNELLE DE LA RELIGION SELON LA THÉORIE SOCIALE DE NIKLAS LUHMANN}

\author{
João Paulo Bachur
}

Mots-clés: Niklas Luhmann; Max Weber; Religion; Théorie des systèmes sociaux; Différenciation fonctionnelle.

L'objectif de ce travail est de rechercher la place de la religion dans le cadre de la théorie de systèmes sociaux de Luhmann afin d'identifier certaines de ses ambiguïtés et contradictions internes. La spécificité de la religion réside dans le fait que la participation à la communication religieuse dépend très étroitement de l'engagement de la conscience par la foi, ce qui difficulte le maintien de sa frontière système/environnement. Nous présentons la religion comme un cas spécifique de différenciation fonctionnelle qui a lieu en tant que réaction à la différenciation des systèmes non-religieux de la société, et comme la privatisation de l'expérience religieuse. La sociologie de Weber est employée pour illustrer notre argumentation d'un point de vue historique. En conclusion, nous suggérons une brève réparation conceptuelle capable d'adapter la théorie des systèmes sociaux à l'observation du phénomène religieux dans la société contemporaine. 